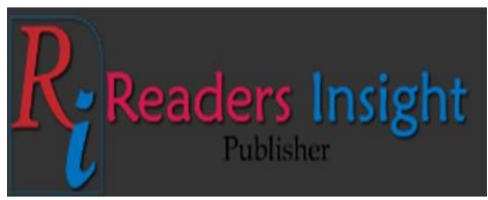

\title{
Impacts of Renal Insufficiency on Hepatic Profile Among Different Chronic Lower Urinary Tract Patients in Quetta
}

\author{
Mohsin Jamal Buzdar ${ }^{1 *}$, Alam Mengal ${ }^{2}$, Talha Shahid Amin ${ }^{3}$, Tahir Hameed ${ }^{1}$, Furqan Ahmed ${ }^{1}$, \\ Farhat Abbas ${ }^{1}$, Hafiza Mehreen Tahir ${ }^{4}$ and Maryum Yousaf ${ }^{1}$.
}

${ }^{1}$ Center of Advanced Studies in Vaccinology and Biotechnology(CASVAB), University of Balochistan(UOB), Quetta, Pakistan

${ }^{2}$ Department of Microbiology, University of Balochistan (UOB), Quetta, Pakstan.

${ }^{3}$ Akhtar Saeed Trust, Lahore, Pakistan.

${ }^{4}$ Department of Biotechnology, Lahore College for Women University Lahore, Pakistan

*Corresponding author: buzdarmohsin786@gmail.com

\begin{abstract}
Primary functions of kidneys is to filter blood by its cells called nephrons, products after metabolism and toxics produced by kidneys upper Urinary tract; and stored in Lower Urinary tract; this helps the body for balance of, electrolytes, water, RBCs, leukocytes, Calcium and blood pressure. If the renal system not work properly it may cause some complications like kidney stones, electrolytes imbalance, which leads to different complications some time may leads to kidney failure it also effects on blood cells, if kidneys not work properly our body retains water and toxics not excreted form blood steam, so patient may leads to death. The prevalence of kidney diseases is significantly increasing in pediatric population, that is may be due to life style changes i.e. diet changes, environmental changes.
\end{abstract}

Keywords: Lower Urinary tract, renal, hapatic, haemotology, blood chemistry

\section{ARTICLE INFORMATION}

Received: 26.07 .2019

Revised: 29.08 .2019

Accepted: 30.09 .2019

DOI: $10.31580 /$ pjmls.v2i3.1118

\section{INTRODUCTION}

Renal system is very complicated system of body, its main function is to excrete the waste from body. It is divided into two parts i.e. upper urinary tract and lower urinary tract; upper parts are formed by kidney and ureters, and lower urinary tract are formed by bladder and urethra. Flow of urine from upper urinary tract to lower urinary tract; plays important role to excrete body waste and it cleans urinary tract [1].

In kidney problems, a most significance problem is enhanced rate of stone formation due to occurrence of Urolithiasis a multifactorial cause and its etiology is not understood until now. Although no single factor is involved in patho-physiology of calculi formation in urinary tract, it may be due to infections, metabolic disturbances, hormonal influence and obstructions in the urinary tract or significantly excretion of urine. To determine kidney problems with hepatic correlations in different ethnic groups in Quetta Pakistan via blood and urine tests to evaluate reason behind specified disease day by day in our region [3]. Moreover, to improve their life style and provide guideline to the patients to avoid from foods and drinks this may create problems such as deposition of stone in urinary tract or electrolyte imbalance. The main objectives of this study are to determine factors effecting on kidney functions and also relationship between blood urea, creatinine, electrolytes and lipid profile [2].

\section{METHODOLOGY OF THE STUDY}

The major goal of study is to review kidney diseases and its effects on liver, and factors effecting kidney and liver directly or indirectly.

\section{Scope of Study}

This work help to determine the core reason of kidney problems.

- It help to change life style.

- It also helps to evaluate the genetic links.

\section{Significance of Study}

This study has very high significance in the Balochistan province to determine the kidney problems in patients residing in Balochistan. It will provide awareness to the people of Balohcistan to reduce risk factors and burden of diesease by following different precautions from physicians. 


\section{Study Design}

The study was carried out at Center for Advanced Studies in Vaccinology and Biotechnology (CASVAB), University of Balochistan, Quetta and Aga Khan Lab which is a private hematology laboratory. The research was conducted after the approval from Advance Studies \& Research Board University of Balochistan, Quetta. Performa /questionnaire was prepared to collect the demographic data and history of the patients. Blood, urine samples was collected from private \& govt clinical Labs.

\section{Research Criteria}

The research was carried out in different age groups of various ethnic population in Quetta Balochistan by collecting their blood sample \& urine sample with a questioner.

\section{Data Collection}

The demographic information was collected from patients from the hospital records at the time of sample collection in clinical Labs. A proper questionnaire was developed for specified study. After consent of patients the demographic information and detailed history was obtained from the study group. The population was divided into six age groups: Group 1 (age 5-11 years), group 2 (age 12-20 years) group 3 (age 21-30 years), group 4(age 31-40 years), group 5(age 41-50) and group 6 (age 51-60 years) respectively, gender, ethnic and area etc.

\section{Sample Collection and Procedures}

Blood and Urine samples were collected from different kidney patients in the Aga khan Lab. $6 \mathrm{ml}$ of blood was collected in serum tubes, after centrifuge the serum is separated and then tested in auto chemistry analyzer to rule out the Renal function test (BUN, Cr, Electrolytes, UDR, ) and LFTs.

\section{Data Analysis}

The data analysis was analyzed statistically by using computer package SPSS version 17 or other. Frequency and percentage was computed to present all the categorical variables by mean, SD, Chi-square and related tests.

\section{RESULTS}

\section{Liver Function Tests (LFTs)}

Liver Function Tests (LFTs) are a group of biochemical measurements that are used to identify patients who are suffering from liver or biliary tract disease. Substances measured include:

- Albumin

- Bilirubin

- Alanine aminotransferase (ALT)

- $\quad$ Aspartate aminotransferase (AST)

- Gamma-glutamyl transferase (GGT)

- Alkaline phosphatase (ALP)

According to table 1 , in 147 male patients the age range, mean and standard deviation age were (25-78) years and 48.10 \pm 12.79. BMI kg/m² , mean \pm standard deviation 25.20-50) 32.19 $\pm 4.16 \mathrm{~kg} / \mathrm{m} 2$. The SBP and DBP, mean as well as standard deviation (70-220) $132.46 \pm 20.28$ and (50-120) $87.80 \pm 12.29$ The FPG, $\mathrm{RPG}$ and $\mathrm{HbA} 1 \mathrm{c}$ range, mean and standard deviation were $(67-418) \mathrm{mg} / \mathrm{dl}$ and $167.85 \pm 60.44 \mathrm{mg} / \mathrm{dl},(138-594) \mathrm{mg} / \mathrm{dl}$ and $279.63 \pm 104.85 \mathrm{mg} / \mathrm{dl}$ and (6.6-14.2\%) and $9.03 \pm 2.01$.
Table 1. T2DM (147) male patient's age, BMI, BP, Fasting, Random and $\mathrm{HbA} 1 \mathrm{c}$

\begin{tabular}{ccccc}
\hline Male & Minimum & Maximum & Mean & St Deviation \\
\hline Age in year & 24 & 76 & 47.05 & 12.79 \\
BMl in kg/m² & 25.20 & 50 & 32.19 & 4.16 \\
SBP mmHg & 70 & 220 & 132.46 & 20.28 \\
DBP mmHg & 50 & 120 & 87.80 & 12.29 \\
FPG mg/dl & 67 & 418 & 167.85 & 60.44 \\
RPG mg/dl & 138 & 594 & 279.63 & 104.85 \\
HbA1c \% & 6.60 & 14.20 & 9.03 & 2.01 \\
\hline
\end{tabular}

In cases of liver disease, blood levels of one or more of these substances might be within the reference range. However, it is unlikely that all the results would be within their respective reference ranges. Together, therefore, the combination of tests is more useful than a single test.

Liver enzymes (ALT, AST, etc.) leak into the blood when liver cells are damaged so, strictly speaking, these tests indicate liver disease rather than liver function. ALT and AST levels provide an indication of the degree of inflammation as well as the possible causes or hepatocellular damage. Similarly, ALP and GGT increases can suggest the presence of obstructive liver disease.

Table 2. Multivariate analysis of parameters predicting patient survival after liver and liver hematology adverse effects in Quetta $(n=200)$.

\begin{tabular}{ccccc}
\hline Variables & $\begin{array}{c}\text { Univariate } \\
\boldsymbol{p} \text { value }\end{array}$ & $\begin{array}{c}\text { Hazard } \\
\text { Ratio }\end{array}$ & $\begin{array}{c}\text { Multivariate } \\
\boldsymbol{p} \text { value }\end{array}$ & $\begin{array}{c}\text { Hazard } \\
\text { Ratio }\end{array}$ \\
\hline Female gender & $<0.0001$ & 1.123 & $<0.0001$ & 1.190 \\
Recepient age & $<0.0001$ & 1.016 & 0.1530 & 1.003 \\
Body Mass Index & $<0.0001$ & 0.990 & $<0.0001$ & 0.984 \\
Creatinine & $<0.0001$ & 1.084 & 0.2413 & 0.979 \\
Dialysis treatment & $<0.0001$ & 1.449 & 0.1198 & 1.114 \\
Renal failure & $<0.0001$ & 1.466 & 0.0067 & 1.200 \\
Renal recovery & $<0.0001$ & 2.829 & $<0.0001$ & 2.648 \\
Comibned liver kidney & $<0.0001$ & 1.221 & 0.9235 & 1.007 \\
transplant & & & & \\
Diabetes & $<0.0001$ & 1.298 & 0.2405 & 1.054 \\
\hline
\end{tabular}

The major finding in this study is that the impact of renal failure is less marked in patients with ALD than in patients with $\mathrm{NASH}$ or hepatitis C. The exact mechanisms by which different etiologies of liver disease impact survival could not be clearly determined from the available UNOS data. One potential hypothesis is that renal failure in patients with ALD is more relevant to hepatic dysfunction, and that renal recovery is more common in ALD than non-ALD patients. According to recent reports, HRS is more common in ALD

\section{DISCUSSION}

Renal disease is big problem in all over the world, as in United States is approximately $13 \%$.in western countries, new research, 1.1 million patients are suffering from Kidney illness all over the globe [4].

Moreover, new research helps the theory that NAFLD may contribute to a higher risk of cardiac disease and other risk factors also some conclusions support the probability that NAFLD is not only a marker also a facilitator of atherosclerosis [8]. CKD disease is a big problem in public health, kidney failure is major problem in Pakistani population, with their poor income and high costs many people can't overcome this disease .It may leads to mental stress, impacts on blood pressure and victims may suffer to hypertensive events [5].

Health is a capacity of an individual to understand the information related to kidney disease, modern studies shows that peoples have limited information about kidney problems, health literacy in kidney patients reported $6 \%$ to $50 \%$. 
Electrolytes balance is very important to maintain homeostasis, and for successful treatment of kidney patients. The kidney is the principal organ for retention and excretion of electrolytes and fluid in healthy individual's .But other factors also play important role to balance electrolyte balance i.e. physiological stress, ant diuretic hormone, parathyroid hormone, and aldosterone. Clinical prevalence of electrolyte imbalance are frequently seen in elderly patients and critical ill patients [2].

Chronic kidney failure is a problem expanding worldwide and effecting socio-economic life of patients [7]. It is a very serious irreversible, progressive weakness in kidney function in which the body's capability to sustain metabolic fluid and electrolyte balance fails, resulting in uremia [6]. The renal function is to regulate composition and volume of blood, and removes metabolic wastes by urination which helps to balance acid/base in the body. It is a progressive disease, defined as impairment of kidney function less than $<60 \mathrm{ml} / \mathrm{min} / 1.7 \mathrm{~m}^{2}$ [7] Or polycystic renal disease [10]. The electrolyte Imbalance may require dialysis in such patients. Old kidney problem Leads to a cystic obsession on renal region which may be environmental or hereditary problem [11].

Healthy life changes help the person and their kidneys healthier for longer period of time, in addition to eating right and prescribed medication only, daily exercise and avoid smoking are also helpful to prolong kidney health. Rate of kidney function decline is differing among racial and ethnic groups, the number of end stage renal disease have been well recognized [9].The studies about kidney function decline ethnic diversity in black or white as compared of kidney function failure among different cultural individuals [12].

Leading cause of death and disability is chronic kidney disease in all over the world. In $1990,27^{\text {th }}$ leading cause of death was CKD. It increased in 2010 to 18th leading cause of death. One, million people died in 2013 due to CKD [5] .Chronic kidney disease is associated with a life threatening disease [2].

Especially in Lower- and middle-income countries of Asia and Africa the acute and chronic harmful consequences is deeply studied, few studies conducted in Pakistan, Bangla Desh and India. South Asian countries have no deep exposure of CKD is available. Hence, for policy makers it is very difficult to prescribe a policy to overcome the chronic kidney disease. In undeveloped countries it is difficult to understand the CKD and communicate the community in clear manner [13].

\section{REFERENCES}

1. J. Coresh, B. C. Astor, T. Greene, G. Eknoyan, and A. S. Levey, "Prevalence of chronic kidney disease and decreased kidney function in the adult US population: Third National Health and Nutrition Examination Survey," American Journal of Kidney Diseases, vol. 41, no. 1, pp. 1-12, 2003.

2. F. Locatelli, P. Pozzoni, F. Tentori, and L. Del Vecchio, "Epidemiology of cardiovascular risk in patients with chronic kidney disease," Nephrology Dialysis Transplantation, vol. 18, no. 7, pp. vii2-vii9, 2003.

3. Mikolasevic, S. Racki, Zaputovic I, V. Lukenda, S. Milic, and L. Orlic, "Nonalcoholic fatty liver disease (NAFLD); a new risk factor for adverse cardiovascular events in dialysis patients," Medical Hypotheses, vol. 82, pp. 205-208, 2014.

4. M. Manco, P. Ciampalini, R. DeVito, A. Vania, M. Cappa, and V. Nobili, "Albuminuria and insulin resistance in children with biopsy proven non-alcoholic fatty liver disease," Pediatric Nephrology, vol. 24, no. 6, pp. 1211-1217, 2009.
5. Swan SK: The search continues-an ideal marker of GFR. Clin Chem. 1997, 43: 913-914.

6. J.K Dowman, J.W. Tolmlinson, and P.N. Newsome,"Systematic review:the diagnosis and staging of non alchoholic fatty liver disease and non-alcholic steatohepatitis ,"A;imentary Pharmacology and Therapeutics, Vol 33no .5pp525540.2011.

7. Wong RJ, Aguilar M, Cheung R, Perumpail RB, Harrison SA, Younossi ZM, et al. Nonalcoholic steatohepatitis is the second leading etiology of liver disease among adults awaiting liver transplantation in United States Gastroenterology. 2015;148(3):547-55.

8. Burra P, Senzolo M, Adam R, Delvart V, Karam V, Germani $\mathrm{G}$, et al. Liver transplantation for alcoholic liver disease in Europe: a study from the ELTR (European Liver Transplant Registry) Am J Transplant. 2010;10(1):138-48.

9. Wong RJ, Chou C, Bonham CA, Concepcion W, Esquivel $\mathrm{CO}$, Ahmed A. Improved survival outcomes in patients with nonalcoholic steatohepatitis and alcoholic liver disease following liver transplantation: an analysis of 2002-2012 United Network for Organ Sharing data. Clin Transplant. 2014;28(6):713-21.

10. Lucey MR, Schaubel DE, Guidinger MK, Tome S, Merion RM. Effect of alcoholic liver disease and hepatitis $C$ infection on waiting list and posttransplant mortality and transplant survival benefit. Hepatology. 2009;50(2):400-6.

11. Garcia-Tsao G, Parikh CR, Viola A. Acute kidney injury in cirrhosis. Hepatology. 2008;48(6):2064-77. [ Angeli P, Rodriguez E, Piano S, Ariza X, Morando F, Sola E, et al. Acute kidney injury and acute-on-chronic liver failure classifications in prognosis assessment of patients with acute decompensation of cirrhosis. Gut. 2014

12. Belcher JM, Parikh CR, Garcia-Tsao G. Acute kidney injury in patients with cirrhosis: perils and promise. Clin Gastroenterol Hepatol. 2013;11(12):1550-8.

13. Ojo AO, Held PJ, Port FK, Wolfe RA, Leichtman AB, Young $\mathrm{EW}$, et al. Chronic renal failure after transplantation of a nonrenal organ. The New England journal of medicine. 2003;349(10):931-40. 